\title{
Innovations in Open and Flexible Education
}

\author{
Kam Cheong Li, Kin Sun Yuen, and Billy Tak Ming Wong, editors \\ Singapore: Springer Singapore, 2018 \\ (XXV + 267 pages, ISBN 978-981-10-7994-8, \$63.23)
}

\section{Reviewed By \\ Elizabeth Yomantas \\ Pepperdine University}

Innovations in Open and Flexible Education is a timely collection of research which examines various aspects of open and flexible education in the global community's changing landscape of teaching and learning. The book is written for professors, academics, researchers, students, educational practitioners, and administrators to learn the latest empirical research in regard to open and flexible education. The book is organized thematically with a focus on four major themes: open/flexible curriculum and pedagogy, mobile and ubiquitous learning, digitized media and open educational resources, and tracking and analysis of student learning. The book includes qualitative and quantitative research studies, empirical and case studies, statistical analyses, descriptive surveys, and interviews.

Part I flows seamlessly as the contributing authors discuss historical perspectives, student perspectives, budget planning, needs assessment, models of the flipped classroom, cross-country analysis, and massive online open courses. Part II focuses on the use of mobile devices, specifically in vocational education and training, preferences and readiness for usage, the use and design of specific apps for learning, and learning management systems. Part III of the book examines digitalized media and open educational resources including game-based learning, flipped massive online open courses, open educational resources, videos in blended learning, and media literacy. The final section of the book, Part IV, analyzes student learning including the use of big data in teaching and learning, instant messaging, application programming interfaces to track learning, reinforcement learning, and the design of data-logging devices.

The findings of this book are exciting. According to Lee, the purpose of flexible learning is to "achieve equity, efficiency, and effectiveness" (31) in education. As the editors note in the introduction to the book, there is a global trend of knowledge becoming more publicly accessible and less reserved for the privileged. As education is becoming more open and consequently more flexible, education at large is more available to all people. This book highlights the latest research on this topic, which may lead to educational stakeholders creating more open and flexible landscapes in their educational communities. As Christian scholars, this must be one of our aims - to make education more inclusive and flexible to welcome and benefit all learners.

The organization and structure of the book is not only informative but is enjoyable to read. The editors selected topics that are connected but remain distinctly different, which creates an interesting and diverse reading experience. Furthermore, the content in this book leads to much introspection on the part of the reader; the reader is challenged to consider what open and flexible pedagogies they have adopted in order to benefit all students. The research provides a fertile ground for discussions of education theory, pedagogy, and praxis. The book is comprised of twenty-three chapters that are written with experiences and perspectives from Asian countries (including Australia) and is a part of a research book series titled Education Innovation. For further work on this topic, it would be valuable for the editors to develop a book series that focuses on research from different continents on open and flexible education. The contents of this book demonstrate the diversity and richness of this topic, so perhaps this text could be expanded into a series. 